\title{
Learning to Be: Emerging Discourse in Awakening Transformation in Education
}

\author{
Vanessa V. Tse and David F. Monk \\ University of Victoria
}

\begin{abstract}
This paper explores the disconnection between knowledge of social and environmental injustices and actions to right them. Through our discussion, we consider possible reasons for this disconnection, whether a lack of knowledge, personal accountability and responsibility, or a fear of being swallowed up in the depths of the suffering in the world. We then critically reflect on our role and the role of education to broach this gap. We adopt O'Sullivan's (2002) transformative learning theory as a guide and suggest that disruptive dialogues, like the one that has guided this paper, can challenge habits of mind, shift perspectives, and lead to action for a better, more equitable world. Ultimately, we conclude that such conversations are organic and ever changing and are integral to education.
\end{abstract}

Keywords: social justice; critical discourse; transformation

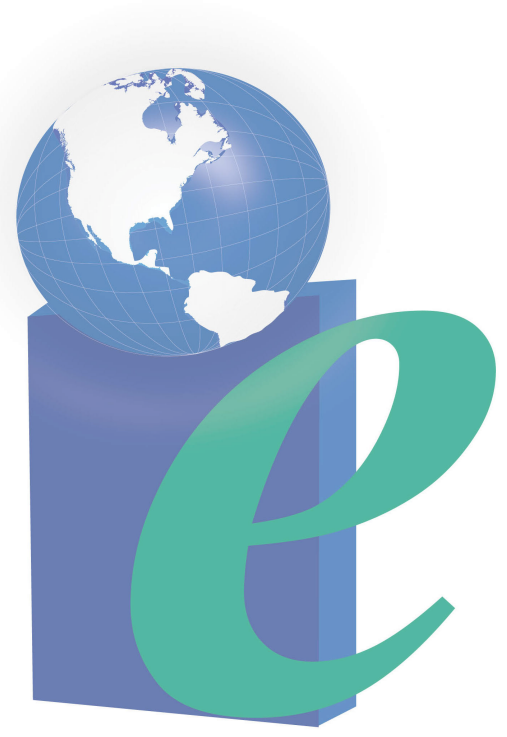




\section{Learning to Be: Emerging Discourse in Awakening Transformation in Education}

As educators, we have witnessed that despite increasing awareness there is not enough meaningful action being taken to engage the ecological and social crises that face our world today. In this paper, we suggest that critical transformative education can cultivate action for systemic change. Our ruminations about how to overcome the disconnection between knowledge of social and environmental injustice inform this work. There are abundant examples of social and environmental ills available; often, they are linked to each other and based in profit making, as is readily observed in the extractive industry (e.g., see the Sierra Club report on the Canadian Tar Sands, 2014). Our goal is to consider how we might go about overcoming current ecological and social crises. Britzman (2003) noted that "experience becomes meaningful only after it is thought about" (p. 231), and it is in this vein that we reflect on and analyse our own lived experiences using Ellis, Adams, and Bochner's (2011) Systematic Sociological Introspection (SSI) process.

Through our critically transformative discussion, we consider reasons, such as a lack of knowledge or an unawareness of injustice, which may be actively preventing transformative solutions. Often, people are unaware of the injustice packaged within their running shoes and garbage bags. We connect this lack of knowledge to a phallocentric, hegemonic worldview that is reinforced through a cult of consumerism, hierarchy, individuality, and the myth of meritocracy. We consider a lack of personal accountability, and a desire not to see and not to understand, intentionally to look away from the crises to avoid accepting responsibility. We suggest that fear of entering into the suffering of the world, that enduring suffering or negotiating peace will consume those who enter into its depths. Our conversations continually revert to themes of transformation and learning to be. We understand transformative learning as outlined by O'Sullivan (2002), who was critical of hierarchies in our society and who linked transformation to a shift in worldview that includes a planetary consciousness. We suggest that critical dialogue, like the one that has guided this paper, can challenge habits of mind, shift perspectives, and lead to action for a better, more equitable world. We advocate for dispositional change in learners and teachers - it is not specific subject matter under scrutiny here, but our entire approach to education.

With Næss (2008), we enter the relentless struggle with "basic questions about who[m] we are, where we are headed, and the nature of the reality in which we are included" (p. 81). This paper is emergent in its unfolding, and entwined within it are deep questions that we do not propose to answer, but to live (Rilke, 2011). In this way, we try to live the questions well and perhaps, as Palmer (1980/2008) proposes, live the contradictions.

This paper is non-linear in many ways, reflecting the emergent and recursive nature of the discourse. What began as questions, spiralled into the poem below, which we feel encapsulates many of the ideas we will discuss. From the poem, we move into the initial question that sparked the dialogue and prompted this endeavour. There are places in this paper where our voices are written in unison and others where we assume the conversational nature of the discourse. We insert text boxes to include the reader in these disruptions and better reflect the nature of our dialogue. The presentation departs from a positivist representation to reflect the meaningful way our ideas fluctuated, disrupted, and merged with each other. Writing this way works with our emergent and ecological understanding of knowing, learning, and transforming. 


\section{Vanessa:}

disrupted

the chestnut

breathing

between the leaves

of culture, society, desks, glinting on

the textbook

born

from this ancient bark.

the old world.

unsettling wind,

disruptive lung

somewhere between

liberation and desolation

unchained.

there in the grass womb

chiasmus.

to come into meaning

or slumber in the

belly of excess.

a heart beat?

rattle too hard

and the disruption

splinters the soul.

the alchemy

of rain, sun, soil

clamouring above and below.

necessary suffering

crawls inside.

cracked.

the shell crumples.

the green

tender and naked

Awakens

This poem is a meditation on the possibility of transformation. The way we are conceptualizing change here seems best represented in the image of a chestnut. The chestnut symbolizes how we often come into this world, connected and born into unjust, dominant paradigms that we will live to perpetuate unless we are disrupted and transformed. In the poem, a disruption occurs that severs the connection to the tree or old world, positing it in the liminal 
space of being and becoming (Tanaka, Stanger, Tse, \& Farish, 2014). Here, we remember that it is events, not ideas, which spark dramatic change (Arendt, 1998). The opportunity is poised for the chestnut to transform into something new. In this fertile space, outside forces work to help it literally grow. For us, a place of tension is the space into which the chestnut falls. In this place it is dormant, neither alive nor dead, but with the potential to be either. Additionally, often the disruption of the chestnut is imperative to change, in that something must separate it from the tree. This metaphor reveals that change is continual and natural, and yet sometimes intervention is required to move us into new ways of being and knowing. Education is one such force that can intervene and cultivate transformative action for social and ecological justice.

Palmer (1980/2008) advocates that we must recover our hearts in order to give them to the world. He suggests that the fear of being overwhelmed by sorrow causes us to refrain from action. However, and paradoxically, "when we give our hearts to the world, our hearts will be broken-broken open to become channels for a love greater than our own. Only as pain is transformed by love will the real revolution come" (Palmer, 1980/2008, p. 32). The chestnut demonstrates the necessity of being broken in order to be transformed; such cracking "places us in question" (Jardine, 2006, p. 173). That is to say, "There's a crack in everything. That's how the light gets in" (Cohen, 1992). As I abide in these complexities, my mind returns to compassion. Compassion comes from the Latin, com (together) and pass (suffer); "a suffering with" (OED, 2013). Here, we come alongside the other (Lingis, 1994) and are reminded that, "One enters into community not by affirming oneself and one's forces but by exposing oneself to expenditure at a loss, to sacrifice. Community forms in a movement by which one exposes oneself to the other..." (p. 12). This exposure is much more difficult than helping or giving aid. It requires us to take "responsibility for the other" (Levinas, 1998, p. 228), and to live alongside the other as a legitimate other (Maturana \& Bunnell, 1999): It requires love.

David: Vanessa, in a conversation that sparked this introspection, you suggested that we all know of the social and environmental problems, and introduced the questions: "Why don't we just change them? What is blocking action? What is blocking change?" I have given much thought to these questions and feel compelled to delve deeper and to examine the role of education in addressing the phenomena.

The context to your question is the film, Ancient Futures: Learning from Ladakh (Page, 1993), which highlights many of the problems ingrained in neoliberalism and normalized in our society. I agree that we need change for social and environmental justice. I do not have the answers; I do not know if it is even possible to find an answer, but perhaps with some discourse we can begin to understand. The topic is massive, with interlinking branches. I will attempt to weave my ideas into something coherent, although it is difficult because they seem to change as I write.

First, I do not think that we do all know about the problems, which is part of the problem. The majority of people in our society do not know. We are deliberately brought up not to know. In his book Madness and Civilization, Foucault (1965) suggests that people allow this ignorance to happen through self-subjection, or normalization. He articulates that people fear marginalization and so strive to conform to societal norms. Sir Ken Robinson (2006) aptly points out that our schools teach people to fit into society, to become clogs in the industrial machine. Similarly, Illych (1970) is extremely critical of the hegemonic nature of schools and makes a compelling case to de-school society. I cannot find fault with these critiques of social norms. Our 
education system falls short of addressing the root causes of the problems embedded deep within the hegemonic structures of our society.

Freire (1970) argues that schooling is an extremely political process. Bouchard (2006) dissects the concepts of human capital and the knowledge economy asserting that it is the powerful in our society that determine what is knowledge, and what it is we need to learn. He explains that education is linked to the economy, and is a highly political process. Similarly, Bourdieu (1984) convincingly argues that education is one important factor in a person's cultural capital, which in turn determines largely where an individual will stand on the socio-economic ladder. As a political process, education becomes a tool to socialize people to hegemonic sameness. Carson and Johnston (2000) label it as "a curriculum of sameness" (p. 76), where education programs are locked in a tradition of conformity.

Related is the separation of school and society. We create institutions of learning that are separated from everyday life, which in turn, separates real life (i.e. life post-school) from learning. Consequently, the idea arises that schools are simply training grounds for a job market (or prison) rather than a process and part of real life, and it is only when one graduates that real life begins.

This separation is significant for me because by creating a disconnection between life and thought, our society does not have a complete education. Under these circumstances, education is merely training that we put our children through because we feel they otherwise cannot survive. Have we always used this term "survive"? It seems to repeat itself often. Is it living, merely to survive? Is this the best we can achieve? Without critical thought or ethical consideration of the world, education is simply training for base individual survival. Schools need to be places where people wake up and learn to live rather than merely to survive. We need to challenge the very assumptions we hold about knowledge and life.

Perhaps we need to consider learning "to be" as a fundamental goal of education, and understand that, as Dewey (1966) argues, learning is an experiential process that cannot be disconnected from the interactions of everyday life. How can we expect people to participate in society when educators do not engage them in this process? As sites of training, schools kill creativity and the ability to think independently (Robinson, 2006). I believe strongly that education needs to foster greater understanding of the world, to include human rights and environmental rights. I would like to be clear here that I am not arguing for a new form of training - one that socially constructs people in a new way. Rather, I am arguing for schools to inspire creativity and to encourage people to value and understand their own experiences. This is why I suggest that we investigate the culture of our schools to evaluate how well they teach students to value their own experiences, how well they foster creativity, and how well they facilitate consciousness of the world. An example of this type of school can be seen in a placebased, eco-centric school in Portland, Oregon, a model introduced by Williams and Taylor (1999). This school uses experiential learning in the community to encourage participation and learning about life outside school walls. It values experiential learning, promotes creativity, and develops critical consciousness of the world and our relationship with it.

Eco-centric schools such as the one introduced by Williams and Taylor have important lessons for educators and education systems to embrace. The education system needs to be a system that supports a lifelong learning process rather than simply training for the work force. A 
more holistic understanding of our very existence is necessary. Education should primarily be about living well, in co-existence with other people and the planet. We need to examine the structures of our current curriculum and critically reconsider the role of our schools. We need to think complexly, not just complicatedly, and on a universal scale. We need to break down the hierarchical, patriarchal way of thinking that our schools are reproducing and begin to put people and the planet before profit. Therefore, it starts from our spirit, our connection to nature, and all things. From there we can zoom into specific curricular issues that could lead to a genuine contribution to us all, to social justice, and to the earth. Orr (1994/2004) puts it well:

The plain fact is that the planet does not need more successful people. But it does desperately need more peacemakers, healers, restorers, storytellers, and lovers of every kind. It needs people who live well in their places. It needs people of moral courage willing to join the fight to make the world habitable and humane. And these qualities have little to do with success as our culture has defined it. (p. 12)

So what does change look like? What is my ideal? What should education or learning be about?

Education should be of spirit and heart first. Here, I think of spirit as the recognition of our interdependence to everything in this world and beyond. This means taking responsibility for our actions and actively participating in the society in which we live, and this is the call of educators. We need to create a dis-orienting place, a place of dis-comfort, a place of challenge to make people jolt a little and perhaps wake up. It must be done collectively, and individually, it is not something that can be dictated. Educators need to facilitate experiences that lead to action based on shifted perspectives and a critical understanding of self and the world.

Foucault (1965) suggests creating minor disruptions to disturb the lives of others, demonstrating to them that there are alternative ways of living. Similarly, Butler (2012) posits that norms function through repetition. She claims that agency is a variation of repetition and that we need to provide alternatives to the entrenched norms. Adult educator O'Sullivan (2002) outlines a framework for conscientization in his transformative learning theory, whereby a disruption in a person's life initiates a process of shifting perspectives of the world and leads to action for social justice.

However, it is difficult; like poetry, you have to bare your soul. It is much easier to (falsely) rationalize with ourselves, use our "practical" intelligence to trick our conscience, our heart, and our spirit into thinking that we are doing enough. Or that it is enough to speak without action.

Paulo Freire's (1970) conception of praxis claims that teaching is an ongoing process of action and reflection. For Freire action was central to the learning process. Like Freire, I would suggest that teacher education programs be infused with a critical understanding of the world. Teachers need to be encouraged to take up critical self-conscientization. They need to begin to understand their own positionality in the world, and their role in it. They need to be empowered with a hopeful understanding that they are active participants in this world and have a responsibility for their activity to be positive rather than negative. They need to understand that people learn from action, not just words and they need to lead by example, or so I have come to feel. 
I share my own transformative learning experience in a master's course in education some years ago, as a method of broadening one's worldview. The course was structured so that we watched a number of films that depicted some of the shortcomings/realities of our way of life. The course readings corresponded with the various issues raised in the films and we discussed them. The course changed my life dramatically, enabling me to think seriously about these issues, and reflect on them. There is one particular point of change that remains clear in my mind. After watching a movie exposing exploitation in the garment industry, The New Rulers of the World (Pilger, 2001), I proceeded to return a new pair of shorts that I had purchased at the GAP, and since then, I have not purchased items from the GAP, Nike, Tommy Hilfiger, Calvin Klein, and other perpetrators of exploitation. This may seem like a small action, but it was a pivotal moment when I recognized my own participation, and realized my own ability to have an impact on the world. It was a truly empowering moment, and I have not looked back. I cannot wear these logos; to do so would advertise my support for companies that engage in exploitation based on huge profits or even greed. This was a turning point for me, when I began to acknowledge my complicity and to act towards changing it. The course was transformative for me, as it disrupted my reading of the world. It shifted my perspective of me and of world systems, beginning a transformative process, as O'Sullivan (2002) points out, leading me to act upon my new understanding. Having learned about the industry, I could not un-know it. So I could not live and continue acting in the same way.

Transformation is difficult, and it led me into unknown territory, as I struggled to find my place. Vanessa, you expressed, that you are not doing enough, and that you could never do enough. I often have the same feelings of inadequacy. I am not strong enough to take that leap of action, but at the same time, I am not sure if I am strong enough not to. Not to take action would mean closing my eyes on injustice, which I know exists. Much like Raskolnikov in Dostoyevski's (1956) novel Crime and Punishment, it would haunt me. There is no going back. My conscience will not allow it. The pain and suffering in this world is just not acceptable to me, it hurts me, and the only way to get rid of it is to remove it from the world, like the cancer that grew in my stomach. Strangely enough, my experience with cancer was what helped me through this, I think. I am learning to be. Maybe my brush with death has made me stronger. Perhaps because I realized that if that does not kill me, then I have no choice but to live. There is only one path for me on this side of life. After having been so incredibly lucky to win this battle with cancer, I simply cannot accept social injustice at the expense of other people.

Learning to live well in the world is a lifelong process for which education needs to prepare us. Merely surviving the grind of everyday life involves dulling the senses; living requires opening the senses and taking action. The task of education should be to ir-rationalize, de-stabilize, and un-civilize_society.

\section{Vanessa:}

\section{Oppressor}

The flutter of a fish tail, the scent of the moon as it rises. All this Earthswelling up, up, 
up. Her fingerprints

on my bones.

The breath

cradling life, its smooth tide

carrying me

in and out

of being and

becoming.

Curriculum

in the twines of grass, the tapestry of a spider, the candle as it burns. My cup overflows.

All this wonder-

Then comes the horror of ashes, poison, pillars of smoke.

The child whose bones ripple under the skin of oppression. Bloated bellies, kingdoms of garbage, scarred earth, hungry hands tugging at my sweater. I reach out, and touch my own shackleenslaved. These quaking hands stained with the blood and bones of all those forgotten in the making of my glittering machine.

Between the desks and the chalkboard. I shudder at their inheritance.

Their shoes scuff the floor as they tumble in and over, wander throughwhat small hands made their world? What story shall I tell them?

Already, their stains form.

What world do we bring forth 
in Babel's glistening shrine?

Eternity in our hearts

with mortality in our hands.

Can the rain wash away the stains

that I was born into?

Many of the issues David and I are wrestling with surface in this poem. When the complexities of life swell to the point of bursting open the seams of what I know-I turn to poetry. Poetry is one of the ways I understand the world and the complexity of living, especially when coupled with my responsibility as a teacher. I am tethered to poetic inquiry (Prendergast, Leggo, \& Sameshima, 2009; Thomas, Cole, \& Stewart, 2012) as a way of negotiating what it means to be human in this world. As I delve into poetry, its mysterious quality surfaces, where I find myself reaching into spaces I do not fully know in words, I try "to give language to the unsayable" (Cahnmann-Taylor, 2009, p. 20).

The poem above sways between wonder and devastation, and curriculum and creation. I confront in these lines that even as I am born into privilege and abundance, I am also born an oppressor. The system leaves everyone shackled, as it drives stakes between cultures, races, genders, and classes.

I am comforted by Palmer's (1980/2008) words, “The capacity to embrace true paradoxes is more than an intellectual skill for holding complex thoughts. It is a life skill for holding complex experiences" (p. xxx). Palmer espouses that we live the contradictions; this tethers me to two poles. One is acknowledging my inherited domination, that my world is heaped full of luxuries at the peril and expense of others. Only with this awareness and the chord of tension can I move forward into change and engage the "vigilant awareness of the work we must continually do to undermine all the socialization that leads us to behave in ways that perpetuate domination" (hooks, 2003, p. 36.). I am stained, as are the students who enter my classroom, though their eyes are not able to perceive it, yet. The second pole is my deep desire to live and be a part of social change. My entire adolescence and adult life has reverberated with an enduring passion to walk alongside those afflicted by systemic poverty. Thus, I must ask, how can we liberate, if we ourselves are not liberated? Maturana and Varela (1987) remind us that,

The knowledge of knowledge compels. It compels us to adopt an attitude of permanent vigilance against the temptation of certainty. It compels us to recognize that certainty is not a proof of truth. It compels us to realize that the world everyone sees is not the world but $a$ world, which we bring forth with others. It compels us to see that the world will be different only if we live differently. (p. 245)

How can we bring forth a new world of sustainability and compassion if we ourselves are enslaved? Therefore, in order for change to occur, we must first disrupt ourselves (M. Tanaka, personal communication, May 29, 2013). Yet, within the last few days, I have realized that this disruption, while painful and necessary, is ultimately life giving. Just as the chestnut must crack open and fade away in order to give way for a new being and new way of being.

\section{David:}

Can the rains wash away the stains that I was born into? 
Time has not changed,

We are our past

The rain but hides

Permanent, un-visible, stains.

Driven by evolution, progress, greed.

We shower but do not cleanse.

Our bloody hands

Exploitation, greed.

Fresh blood .

Curriculum. Education. Learning to was, will be and be

Acknowledge our privilege,

the cost paid by others.

Open nuts. Stop bloodshed. Drive change in society.

What change? Am I right? Is my vision correct? The questions persist. David, you crack open a tension within me on several issues. This reference to rain and water symbolizes a perceived cleansing of our spirit. As a society, we collectively ignore the injustices and heritage of colonialism and pretend that they have been washed away, but this is a choice not to acknowledge our role of tacitly upholding and reproducing the same injustices. Vandana Shiva (1992) suggests that the affluent have created a protective barrier between their lifestyles and those of the people and the environment that they exploit, so that the damage caused has become largely invisible to them. In this vein of thought, I think the blood of which you speak needs to be made visible again, in order to understand privilege and take action to adjust and address injustice, I mean really address it, not just make a few changes, and keep these barriers. Schools do not address these deeply embedded issues. We need to research the root of the problems, address the underlying systemic causes, and embody solutions through informed action. Action is being; education is action; learning is lived experience. Education should drive change in society, not reinforce dominant norms and power structures. Education should be about knowledge. About being. Here I return to the structures that shackle us in a state of apathetic complacency. Chomsky (1997) identified schools as one of these structures, intentionally reproducing ignorance and maintaining class divisions (p. 27).

Another intriguing question you ask is, "How can we bring forth a new world of sustainability and compassion if we are ourselves enslaved?" Foucault (1965) suggests that we are enslaved to ourselves, that we subject ourselves to living within the norms of society. For me, this society is one based on a positivistic paradigm of thought, enslaved if you will to the concept of meritocracy; survival of the fittest is our mantra, allowing us to fall into this paradox of humans having the right to conquer our environment, and taking advantage of others. This leads to a false sense of individualism and rationalization of greed. Rational thought is a term at the centre of the issue, so I would like to address it. 
Abram (1996) adroitly points out that "civilizing" and "caring for" others is the commonly used rationale for exploitation of other peoples in the past through colonialism and slavery. Choudry and Kapoor (2013) comment on this same idea, connecting it to the present day form of ongoing economic exploitation under the guise of "development" and "jobs." Our current rational way of living dictates that we can burn wheat while starving people look on. Our logic dictates that the Gap, Nike, and Wal-Mart can force people to live in slave-like conditions, earning a wage that they cannot survive on while the people they work for can make enormous profits. There appears to be no room for conscience in the current Western rationality. And we call this civilized?

We are chained to a system of laws that is driven by greed, forgetting the very ethics it is meant to represent. The idea to move out of the realm of orderly rhetoric and into the realm of passion, values, and emotions is not tolerated in our current paradigm. For me, this does not make sense. If not passion, then what do we have? We should follow our hearts and spirits before all else.

Framing critical thought as a negative is overwhelming, disempowering, and can lead to inaction. In Pedagogy of Hope, Freire (2004) deconstructs the notion of hope and hopelessness. For Freire, hope is an ontological need, and hopelessness is paralyzing and demoralizing. Freire (2004) suggests that in a state of hopelessness, "we succumb to fatalism, and then it becomes impossible to muster the strength we absolutely need for a fierce struggle that will re-create the world" (p. 2). He asserts that "hope as an ontological need, demands an anchoring in practice" (Friere, 2004, p. 2), and reinforces that "one of the tasks of the progressive educator...is to unveil opportunities for hope, no matter what the obstacles may be" (p. 3). Change then must be considered as a positive force. It is exciting, it is fun, and it is ongoing.

The other question that raises itself in my mind is this issue of guilt. In assuming guilt, we risk feeling pity and benevolence. Again, we are deciding, and thus, we hold onto power, and consider ourselves superior. This is especially risky when we speak about inherited guilt, where we somehow dis-associate ourselves from the past even while assuming guilt.

However, here as we re-read, Vanessa challenges the colonial connotation of my use of the term pity, and I think she is right. Our friend across the table notes that we are embodying the struggle we are trying to articulate-language comprehension is relative and rooted in individual history.

Finally, we need to be cautious with our assumptions. How certain can we be that we are correct? What worries me is that I am perhaps overly certain about the past, too critical about the present, and deciding what the future should be. Life is complex, there is no set course or path trodden; it is not a racetrack but a maze in constant flux. Merely, believing in something does not make it true. In fact, the stronger the belief in a definite, the greater the boundaries are that we erect. This is why we need to be careful about how we proceed.

Vanessa: Thank you for your poem and thoughtful words. Many of the things you touch on in the poem resonate deeply with me-but more than resonate, as often I feel a burning inside. Early in your writing, you touch on the purpose of education, which for you is to provoke activism. Your purpose intersects with issues you discuss at the end with regard to certainty. These issues are deeply aligned with the work of Maturana and Varela (1987) and the quote I cited in my previous writing. I see in your words that the purpose of education both in and out 
schools is to shake the chestnut out of the tree, essentially to disrupt those who are not already engaged in social and ecological dilemmas from their complacency to enter meaningfully into the realities of the world. I also feel that education must give us the tools to live well together and with all our "relations" to use the term from Tsartlip Elder, Marie Cooper (personal communication, March 2012). Furthermore, we might also hope to imbue children with a way of being that Næss (2008) deems, comprehensive, which for him was to be mature in all significant relationships with all living organisms.

As we examine the purpose of education, we return to the construct of thought and that "this connection between action and experience, this inseparability between a particular way of being and how the world appears to us, tells us that every act of knowing brings forth a world" (Maturana \& Varela, 1987, p. 26). Palmer's (1980/2008) words interlace here: "Since the world is in us, we are responsible for the world - and the shape the world takes depends on how we live our lives" (p. 36). Furthermore, Capra (1996) asserts that, "relationships are the essence of the living world" (p. 173). My thinking becomes entangled, but one distinct thought surfaces through Maturana and Varela (1987): The world will only change if we are changed. This seems so small, but hope compels me. Thus, education is not merely a tool for change, but an integral, organic element of bringing forth a new world.

I wonder where spirit joins the liminal space between the disruptor and disrupted. As one acknowledges spirit, it often leads one to the profound realization of the interconnectedness of all life; "ecological awareness is spiritual in its deepest essence" (Capra, 1996, p. 7). This plunges us again into a world of questions, indeed, as Capra suggested the heart of deep ecology is to invite profound questions, and this is the soul of a paradigm shift. Here we turn to the language of spirit. Palmer (1980/2008) eloquently reminds us that the terrain of the spiritual life "is the non-rational, not the irrational" (p. 7). Our rational thinking often limits and chokes us from entering into a deeper reality: our connection with all living entities. When I centre myself in this place, I find that the stains I was born into are not ones that must be cleansed, but healed, and only love can heal. "The only emotion that broadens vision and expands intelligent behaviour is love" (Maturana and Bunnell, 1999, p. 61). In this way, love is the ultimate disruption. This reminds me of the centrality of love in the transformation of education, because, "to be guided by love is to live in community with all life" (hooks, 2003, p.163).

Vanessa and David: In the process of writing this paper, we engaged in critical discourse that has forced us to reflect on our ways of being and acting in the world. We feel these kinds of dialogues are important to disrupt the current systems of domination and stimulate the type of change that can only be expressed as transformation contingent on thoughtful action. Doll (1993) asserts in A Post-Modern Perspective on Curriculum that dialogue is necessary for transformation. Indeed, without dialogue there is no possibility for transformation. Too often, we undervalue the power of careful discussion that explores the ways in which we come to dwell in ideas. How we think, enables what we do and how we live. In this way, we advocate for more critical and relational dialogues that disrupt the spaces in which we currently dwell. It then becomes possible for us to share our stories, allow our ideas to collide into one another and perhaps, find ways of living differently in this world.

Our ruminations about how to overcome the disconnection between knowledge of social and environmental injustice, through transformative education for action, inform this work. We wanted this paper to reflect the animate nature of how ideas are born and churned within a 
relational space. Our ideas have emerged in a wild tempest of emotion, spirit, and intellect constantly in flux as we write, rewrite, read, discuss, and write again. Much akin to walking along the surf and entering into another's lived reality; we would turn over a stone only to discover a living system dwelling beneath in the enclave. Suddenly, these tiny organisms spill over and as we begin to recognize them they disperse in their complex interactions. In the same way, our conversations reflect the ever-emergent and shifting nature of ecology.

The questions we have addressed here are complex and contentious; they are more than sites of provocation, but are passions that compose our purposes as educators. However, our wonderings are incomplete. We approach them with a spirit of hope and this calls us to action, as "the term itself does not hold a meaning in the abstract apart from its enactments" (Oberg, Blades, \& Thom, 2007, p. 130). Perhaps this returns us to a place we have known for a long time, but did not fully understand - a place of paradox and questions so vast that we fear if we take one step into its yawning mouth we will be unable to return to the world we once knew. Yet to deny the invitation is to deny life. We invoke the words of Rilke (2005):

Let everything happen to you: beauty and terror.

Just keep going. No feeling is final.

Don't let yourself lose me.

Nearby is the country they call life.

You will know it by its seriousness.

Give me your hand. (p. 119) 


\section{References}

Abram, D. (1996). The spell of the sensuous. New York, NY: Vintage Books.

Arendt, H. (1998). The human condition (2nd ed.). Chicago, IL: University of Chicago Press.

Bouchard, P. Human capital and the knowledge economy. In T. J. Fenwick, T. Nesbit, \& B. Spencer (Eds.), Contexts of adult education: Canadian perspectives (pp. 164-172). Toronto, ON: Thompson Educational Publishing.

Bourdieu, P. (1984). Distinction: A social critique of the judgment of taste. Cambridge, Mass: Harvard University Press.

Britzman, D. (2003). Practice makes practice. New York, NY: State University of New York Press.

Butler, J. (2012). A politics of the street. Youtube: Wall Institute. Retrieved from https://www.youtube.com/watch?=v-bPr7t4tgA

Capra, F. (1996). The web of life: A new scientific understanding of living systems. New York, NY: Anchor Books.

Cahnmann-Taylor, M. (2009). The craft, practice, and possibility of poetry in educationalresearch. In M. Prendergast, C. Leggo, \& P. Sameshima (Eds.), Poetic inquiry: Vibrant voices in the social sciences. Rotterdam, Netherlands: Sense Publishers.

Carson, T., \& Johnson, I. (2000). The difficulty with difference in teacher education: Toward a pedagogy of compassion. The Alberta Journal of educational Research, XLVI(1), 75-83.

Chomsky, N. (1997). Class warfare: Interviews with David Baristian. Vancouver, BC: New Vancouver Press.

Choudry, A., \& Kapoor, D. (Eds.). (2013). NGOization: Complicity, contradictions and prospects. London, England: Zed Books.

Cohen, L. (1992). Anthem. The future [CD]. Columbia Records.

Compassion. (2013). Oxford English Dictionary. Retrieved from http://oxforddictionaries.com/

Dewey, J. (1966). Democracy and education. London, England: Collier Macmillan Limited

Doll, W. E. (1993). A Post-Modern Perspective on Curriculum. New York, NY: Teachers College Press.

Dostoyevski, F. (1956). Crime and Punishment. (C. Garnett, Trans.). New York, NY: Random House.

Ellis, C., Adams, T. E., \& Bochner, A. P. (2011). Autoethnography: An Overview. Forum: Qualitative Social Research, 12(1). Retrieved from: http://nbnresolving.de/urn:nbn:de:0114-fqs1101108

Foucault, M. (1965). Madness and civilization: A history of insanity in the age of reason. (R. 
Howard, Trans.). New York, NY: Pantheon Books.

Freire, P. (2004). Pedagogy of hope: Reliving pedagogy of the oppressed. (R. Barr Trans). New York, NY: Continuum International Publishing Group.

Freire, P. (1970). Pedagogy of the oppressed. (B. Ramos, Trans.). New York, NY: Continuum. hooks, b. (2003). Teaching community: A pedagogy of hope. New York, NY: Routledge.

Illych, I. (1970). Deschooling society. New York, NY: Harper and Row Publishers.

Jardine, D. W. (2006). Curriculum in abundance. Mahwah, NJ: Lawrence Erlbaum Associates.

Levinas, E. (1998). Entre nous: On thinking-of-the-other. (M. B. Smith \& B. Harshav, Trans.). New York, NY: Columbia University Press.

Lingis, A. (1994). The community of those who have nothing in common. Bloomington and Indianapolis, IN: Indiana University Press.

Maturana, H., \& Bunnell, P. (1999). The biology of business: Love expands intelligence. Reflections, The SoL Journal, 1(2), 58-66.

Maturana, H., \& Varela, F. (1987). The tree of knowledge: The biological roots of human understanding. Boston, MA: Shambhala.

Næss, A., Drengson, A.R., \& Devall, B. (2008). Ecology of wisdom: Writings by Arne Ncess. Berkeley, CA: Counterpoint.

Oberg, A., Blades, D., \& Thom, J. S. (2007). Untying a dreamcatcher: Coming to understand possibilities for teaching students of Aboriginal inheritance. Educational Studies, 42(2), 111-139.

Orr, D. W. (1994/2004). Earth in mind. Washington, DC: Island Press.

O'Sullivan, E. (2002). The project and vision of transformative education: Integral transformative learning. In E. O’Sullivan, A. Morell, \& M. O’Connor (Eds.), Expanding the boundaries of transformative learning (pp. 1-13). New York, NY: Palgrave.

Palmer, P. (1980/2008). The promise of paradox: A celebration of contradictions in the Christian life. San Francisco, CA: Jossey-Bass.

Page, J. (Producer). (1993). Ancient futures: Learning from Ladakh [Documentary]. United States: International Society for Ecology and Culture.

Pilger, J. (Producer). (1991). The new rulers of the world [Documentary]. United States: Carlton Television. Retrieved from http://johnpilger.com/videos/the-new-rulers-of-the-world

Prendergast, M., Leggo, C., \& Sameshima, P. (Eds.). (2009). Poetic inquiry: Vibrant voices in the social sciences. Rotterdam, Netherlands: Sense Publishers.

Rilke, R. M. (2005). Book of hours: Love poems to God. (A. Barrows \& J. Macy, Trans.). New York, NY: Riverhead. 
Rilke, R. M. (2011). Letters to a young poet. (M. Harman, Trans.). Cambridge, MA: Harvard University Press.

Robinson, K. (2006). How schools kill creativity. TED Talks. Retrieved from http://www.ted.com/talks/ken_robinson_says_schools_kill_creativity.html

Shiva, V. (1992). Resources. In W. Sachs (Ed.), The development dictionary (pp. 206-218). Johannesburg, South Africa: Witwatersrand University Press.

Sierra Club Canada (2014). Tar sands, environmental justice \& health. Sierra Club Canada. Retrieved from http://www.sierraclub.ca/en/tar-sands/publications/tar-sandsenvironmental-justice-health

Tanaka, M., Stanger, N., Tse, V., \& Farish, M. (2014). Transformative inquiry iBook inApple (version 4.0) available at iTunes and: http://transformativeinquiry.ca/downloads

Thomas, S., Cole, A., \& Stewart, S. (Eds.). (2012). The art of poetic inquiry. Big Tancook Island, Nova Scotia: Backalong Books.

Williams, D., \& Taylor, S. (1999). From margin to center: Initiation and development of an environmental school from the ground up. In G. Smith \& D. Williams (Eds.), Ecological education in action: On weaving education, culture, and the environment (pp.79-102). New York, NY: State University of New York Press. 